\title{
Erratum to: Thermophysical Properties of Liquid Aluminum
}

\author{
MATTHIAS LEITNER, THOMAS LEITNER, ALEXANDER SCHMON, \\ KIRMANJ AZIZ, and GERNOT POTTLACHER
}

DOI: $10.1007 / \mathrm{s} 11661-017-4091-0$

(C) The Minerals, Metals \& Materials Society and ASM International 2017

\section{Erratum to: METALLURGICAL AND MATERIALS TRANSACTIONS A DOI: $10.1007 / \mathrm{s} 11661-017-4053-6$}

IN the Results and Discussion section of the original article there were several errors missed by the publisher as listed below. The original article was corrected.

In the first paragraph, third sentence, the corrected sentence is as follows:

Furthermore, a collection of data values in steps of $50 \mathrm{~K}$ is given in Table II.
In Section C, Enthalpy, in the fourth paragraph, 13th line, 2.9 pct is corrected as +2.9 pct.

In Section F, Surface Tension, the third sentence is corrected as follows:

Due to the low radiance in the visible spectrum of aluminum at low temperatures, data could be obtained just as close as $1014 \mathrm{~K} \pm 21 \mathrm{~K}$ to the melting point.

MATTHIAS LEITNER, THOMAS LEITNER, and GERNOT POTTLACHER are with the Institute of Experimental Physics, Graz University of Technology, NAWI Graz, Petersgasse 16, 8010, Graz, Austria. Contact e-mail: pottlacher@tugraz.at ALEXANDER SCHMON is with the Patent Attorney Dipl.-Ing. Dr. Gernot Wirnsberger, Leoben, Austria. KIRMANJ AZIZ is with the EPCOS OHG a TDK Group Company, Deutschlandsberg, Austria.

The online version of the original article can be found under doi: 10.1007/s11661-017-4053-6.

Article published online April 7, 2017 